\title{
Assess the Practice Regarding Safety Measures Used By Nurses While Administering Chemotherapy Drugs
}

\author{
Darshana Kumari* \\ Department of Child Health Nursing, SRMM College of Nursing, India
}

Received: January 12, 2018; Published: January 23, 2018

*Corresponding author: Darshana Kumari, Department of Child Health Nursing, SRMM College of nursing, Sawangi (Meghe) Wardha, Maharashtra, India, Tel: 8421960453; Email: Kumaridiya90@gmail.com

\begin{abstract}
Background: In a recent study of outpatient nurses, participants reported significant unintended skin and eye exposure to chemotherapy Friese, et al. In this study, the author concludes that the overall rate of exposure decreases when nurses report adequate staffing and resources (2011). This implies that nurse-patient ratios and workplace demands contribute to the problem of mishandling chemotherapy. Therefore, these results implicate the need for adequate staffing and resources as well as increased staff compliance to established practice standards in order to better protect oncology nurses. Other contributing factors identified in system failures that result in an unsafe work environment include lack of awareness of personal and public risks of exposure, poor communication, and direct interruptions and/or distractions while preparing to administer medications Ashley et al. [1].
\end{abstract}

Objectives: To assess the practice regarding safety measures used by nurses while handling chemotherapy drugs.

Method: In this Study the structured checklist was used to see the practice regarding safety measures used by nurses while handling chemotherapy drugs.

Result: Assessment of nurse's practice while administering chemotherapy drug. Majority of samples 74 (74\%) were having excellent practice while administering chemotherapy drug, 24 (24\%) of nurses were having good practice while administering chemotherapy drugs, [2] (2\%) of nurses were having average practice while administering chemotherapy drugs. Maximum score was 16 and minimum score was 7.

Conclusion: After the detailed analysis, this study leads to the following conclusion, Assessment of nurse's practice while administering chemotherapy drug. Majority of samples were having excellent practice while administering chemotherapy drug.

Keywords: Oncology; Chemotherapy Antineoplastic; Personal protective equipment

Abbreviations: PPE: Personal Protective Equipment; JOHP: Journal of Hematology Oncology Pharmacy

\section{Introduction}

An extensive review of comprehensive standards associated with hazardous drug administration and the use of personal protective equipment (PPE) may be necessary to determine if policies and regulations need to be updated to correspond with current evidence Walton et al. In fact, one study explains that nurses in particular are at an increased risk of chemotherapy exposure due to the large amount of hazardous drugs administered in outpatient settings as well as the lack of enforcement of existing policies in the workplace Friese, Himes-Ferris, Frasier, McCullag, \& Griggs, et al. Minimal medical surveillance of healthcare workers may also contribute to the lack of awareness of this practice problem. The Oncology Nursing Society recommends that in order to provide quality care and maintain safety standards, nurses must be competent in oncology nursing practice and have an awareness of risks amid their workplace.

A major facet of this competency is that nurses must be remaining educated and regularly engage in mandatory updates Crannell [3]. Polovich and Clark 2012 pose that several barriers may be influencing the practice problem of unintended exposure to chemotherapy and indicate that political factors regarding mandatory national safety guidelines need to encourage employers to acknowledge this safety issue. However, existing studies suggest that despite the existence of policies and procedures, contamination are likely still occurring Polovich \& Clark. 


\section{Background}

Health risks for individuals (e.g. healthcare workers and pharmaceutical plant employees) occupationally exposed to cytostatic drugs. Cytostatic drugs possess toxic properties and may therefore cause mutagenic, carcinogenic and teratogenic effects. Hence, individuals handling these drugs in the course of their employment may face health risks. For this reason, it is important to monitor occupational exposure to these drugs. An overview of exposure monitoring methods is presented and their value is discussed. Most studies involve nonselective methods for biological monitoring and biological effect monitoring, such as the urinary mutagen city assay and analysis of chromosomal aberrations and sister- chromatid exchanges in peripheral blood lymphocytes [4]. The disadvantages of these biological methods are that their sensitivity is low and it cannot be proved beyond any doubt that the results found were caused by occupational exposure to cytostatic drugs. For occupational health services it is important to have sensitive and specific methods for monitoring exposure to cytostatic drugs. One of the most promising methods seems to be the determination of cyclophosphamide in urine using gas chromatography tandem mass spectrometry.

Several studies have demonstrated exposure to cyclophosphamide and other cytostatic drugs, even when protective measures were taken and safety guidelines were followed. To estimate the magnitude of any health effects arising from this exposure, we calculated the risk of cancer due to occupational exposure to cyclophosphamide on the basis of available human and animal dose-response data and the amounts of cyclophosphamide found in urine. The initial results show an extra cancer risk for pharmacy technicians and nurses [3]. A survey of experienced and certified oncology nurses also suggests that although perceived risk of harm and knowledge of personal protective equipment was high, the total use of precautions was low Polovich \& Martin. A recent study that explored patterns of personal protective equipment use among oncology nurses, that those working in private practices were less likely to adhere to current safety guidelines than those employed elsewhere Polovich \& Martin.

\section{Objectives}

To assess the practice regarding safety measures used by nurses while administering chemotherapy drugs.

\section{Methodology}

a) Research Design- This study includes the descriptive research design.

b) Sample: This study includes the staff Nurses who are working in the oncology hospital/cancer hospital.

c) Sample Size: This study includes the staff Nurses who are working in the oncology hospital/cancer hospital. Sample size was 100 staff nurses.

d) Setting of the Study: The study was undertaken in Saint Tukdoji Maharaj Cancer Hospital, Nagpur. e) Sampling Technique: Non probability purposive sampling technique is used for this study.

\section{Variables}

Independent Variable: The independent variable in this study is nurses working in the hospital.

Dependent Variable: The dependent variables in this study is practice regarding safety measures while handling chemotherapy drugs

\section{Criteria For Sample Selection}

\section{Inclusion Criteria}

a) Staff Nurses who are working in oncology department

b) Those who knows Hindi, Marathi and English language.

\section{Exclusion Criteria}

a) Those who are experience not more than 3years.

\section{Method Of Data Collection}

\section{Method of Data Collection}

The data shall be collected from all the nursing staff who is working in oncology department. The participant shall be explained about the purpose of the study. Written consent shall be taken before recruiting the subjects for the study.Check list shall be given to the participants to collect the data.

\section{Analysis}

Collected data were organized in tabular form for analysis. The collected data was analyzed by using descriptive statistics and inferential statistics. Association is made with the help of T- test, one way ANOVA test. The data is presented in the form of tables and graphs [5].

\section{Results}

The data are based on the objectives of the study. Data presented under the following headings.

\section{Section 1- Demographic Variables}

a) Distribution of nurses according to their age in years shows that $64 \%$ of the nurses belonging to $21-30$ years, $33 \%$ of nurses belonging to $31-40$ years, $1 \%$ belonging to $41-50$ years and $2 \%$ nurses belonging to above 51 years respectively.

b) Distribution of nurses according to their gender shows that $15 \%$ were belonging to male gender and $85 \%$ were belonging to female gender respectively.

c) Distribution of nurses according to their marital status shows that $34 \%$ of nurses were single, $66 \%$ of nurses were married and no widowed respectively.

d) Distribution of nurses according to their number of living children shows that $24 \%$ of nurse were one living child, $31 \%$ of nurses were two living children, $6 \%$ of nurses were more than two children and $39 \%$ of nurses were no child respectively. 
e) Distribution of nurses according to their number of abortion shows that $21 \%$ of nurses were one abortion, $4 \%$ of nurses were two abortions, $1 \%$ of nurses were more than two abortion and $74 \%$ of nurses were no abortion respectively.

f) Distribution of nurses according to their previous training shows that $8 \%$ of nurses were having previous training and $92 \%$ of nurses were having no previous training respectively.

g) Distribution of nurses according to their education qualification shows that $66 \%$ of nurses were belonging to RGNM, 28\% of nurses were belonging to Basic.B.Sc/Post Basic.BSc nursing, $2 \%$ of nurses belonging to M.Sc nursing respectively.

h) Distribution of nurses according to their working experience shows that $70 \%$ of nurses were belonging to 1-5 years experience, $28 \%$ of nurses were belonging to $6-10$ years experience, $2 \%$ of nurses belonging to above 16 years working experience respectively.

i) Distribution of nurses according to their regular medical checkup shows that $31 \%$ of nurses were belonging to no regular checkup, $68 \%$ of nurses were belonging to every $2-5$ years regular checkup and $1 \%$ of nurses belonging to more than 5 years regular checkup respectively.

\section{Section II}

Table 1: Assessment of the practice regarding safety measures used by nurses while administering chemotherapy drugs.

\begin{tabular}{|c|c|c|c|}
\hline \multirow{2}{*}{$\begin{array}{c}\text { Assessment of } \\
\text { practice while } \\
\text { administering } \\
\text { chemotherapy } \\
\text { drugs }\end{array}$} & $\begin{array}{c}\text { Percentage } \\
\text { score }\end{array}$ & $\begin{array}{c}\text { Assessment of practice while } \\
\text { administering chemotherapy } \\
\text { drugs }\end{array}$ \\
\cline { 3 - 4 } & & Frequency & $\begin{array}{c}\text { Percentage } \\
\text { (\%) }\end{array}$ \\
\hline Poor & $1-4(0-20 \%)$ & 0 & $0 \%$ \\
\hline Average & $5-8(21-40 \%)$ & 2 & $2 \%$ \\
\hline Good & $9-12(41-60 \%)$ & 24 & $24 \%$ \\
\hline Excellent & $13-16(61-80 \%)$ & 74 & $74 \%$ \\
\hline Minimum score & & 7 & \\
\hline Maximum score & \multicolumn{3}{|c}{} \\
\hline Mean score & \multicolumn{3}{|c|}{$13.64 \pm 1.65$} \\
\hline
\end{tabular}

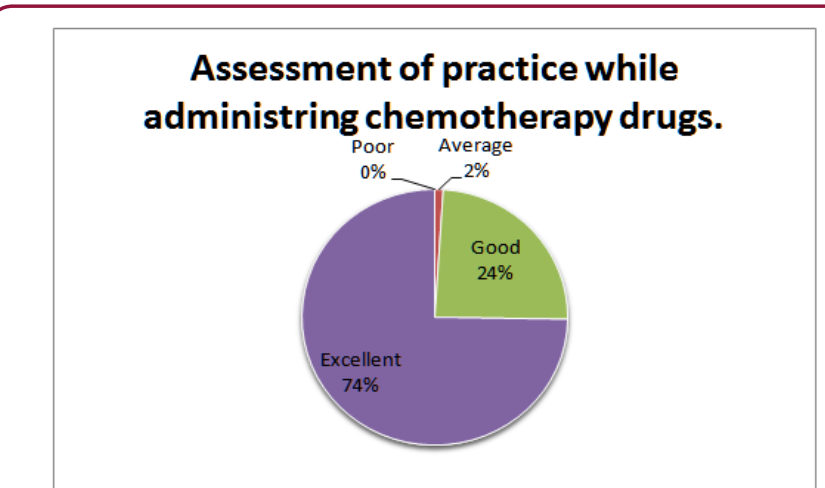

Figure 1: Assessment of practice while administering chemotherapy drugs.
The above table no. 1 shows the assessment of nurses' practice while administering chemotherapy drug. Majority of samples 74 (74\%) were having excellent practice while administering chemotherapy drug, 24 (24\%) of nurses were having good practice while administering chemotherapy drugs, $2(2 \%)$ of nurses were having average practice while administering chemotherapy drugs. Maximum score was 16 and minimum score was 7 (Table 1) \& (Figure 1).

\section{Discussion}

In our study the nurses are having excellent administration skill while administering the chemotherapy drugs, The supporting studies are Journal of hematology oncology pharmacy (JOHP), March 2011, vol. 1 Robert S. Mancini, Pharm D, BCOP The literature search yielded 110 articles for evaluation. The original 110 articles provided evidence for 62 potential chemotherapy combination sequences. Based on the types of studies examined, 27 potential sequences remained clinically undefined because of a lack of clinical relevance of the studies that supported them, 21 combinations were justified with a particular sequence, and 14 combinations had evidence that sequence was irrelevant to outcomes [6]. From these data, a chemotherapy administration sequence chart was created as a reference for nurses and pharmacists.

Gibson F et al. [7] 44 conducted a descriptive study to explore the knowledge, attitude and beliefs of nurses who administer chemotherapy to children and young people, 286 nurses were the samples of study. The study showed that nurses new to chemotherapy administration were initially anxious about their role and due to their anxious state makes drug error. Education and support from colleagues appears to have had a positive effect on reducing worry and increasing competence. Polovich M, \& Clark PC [8] 61 conducted a cross-sectional study, among 165 nurses who were reported handling chemotherapy in oncology centers across the United States using mailed survey method, to examine relationship among factors affecting nurses use of hazardous drugs, safe-handling precautions, identify the factors that promote over interfere with the hazardous drug precaution use and determine managers perspective on the use of hazardous drug safe handling precaution. The result showed that circumstances in the work place interfere with the nurses to use precaution during drug preparation [9].

Brown CG [10] 38 conducted a prospective study to assess the value of oncology nursing certification. A total of 940 Oncology nurses participated and completed a demographic survey and the perceived value of certification tool. Most were Caucasian women. $36 \%$ were staff nurses. 19\% were nurse managers and $10 \%$ were advance practice nurses. A high value of certification was reported. Both certified and non-certified nurse's valued certification. Increasing institutional reorganization and financial support could improve nurses' certification rates and ultimately result in improved patient care. Creaton EM [11] 40 conducted a descriptive study among the inpatient oncology staff of St Elisabeth's hospital in Boston. The programme consist of theoretical and practical component in which in-patient oncology nursing staffs were highly 
motivated to expand their knowledge base for cancer patient care and expressed interest in chemotherapy administration.

Verity R et al. 72 conducted a descriptive study to explore the work of nurses who administer chemotherapy. The study was conducted across 26 London hospitals providing cancer services. 244 nurses were the study participants, the findings highlighted the value of formal educational preparation in chemotherapy prior to undertaking the aspect of nursing. The result reinforced that co ordinate education and training strategy for chemotherapy practice is warranted to underpin safe and effective practice in this area [12].

\section{Conclusion}

After the detailed analysis, this study leads to the following conclusion. Assessment of nurses practice while administering chemotherapy drug. Majority of samples were having excellent practice while administering chemotherapy drug. There is therefore, a need to improve the safety of the work environment; make available protective equipment develop standard practice guidelines for oncology nurses.

\section{References}

1. Prevention guide safe handling of hazardous drugs by Asstsas p. 4-10.

2. (2006) American Society of Health System Pharmacists (2006) ASHP guidelines on handling hazardous drugs. American Journal of Health System Pharmacists 63(12): 1172-1193.

3. Hansen J, Olsen JH (1994) Cancer morbidity among Danish female pharmacy technicians. Scandinavian Journal of Work and Environmental Health 20(1): 22-26.
4. Ben Ami S, Shaham J, Rabin S, Melzer A, Ribak J (2001) the influence of nurses' knowledge, attitudes, and health beliefs on their safe behaviour with cytotoxic drugs in Israel. Cancer Nursing 24(3): 192-200.

5. PV Rekhadevi, N sailaja, Chandrasekhar M, Mahboob M, Paramjit Grover (2007) Genotoxicity assessment in oncology nurses handling antineoplastic drugs. Mutagenesis 22(6): 395-401.

6. Bouraoui S, Brahem A, Tabka F, Mrizek N, Saad A, et al. (2011) Assessment of chromosomal aberrations, micronuclei and proliferation rate index in peripheral lymphocytes from Tunisian nurses handling cytotoxic drugs. Environ Toxicol Pharmacol 31(1): 250-257.

7. Valanis B, Vollmer WM, Labuhn K, Glass A, Corelle C (1999) Antineoplastic drug handling protection after OSHA guidelines: Comparison by profession, handling activity and work site. Journal of Occupational Medicine 34(2): 149-155.

8. Kosgeroglou N, Ayranci U, Ozerdogan N, Demirustu C (2006) Turkish nurses' information about and administration of chemotherapy drugs. Journal of clinical nursing 15(9): 1179-8725.

9. Tiffany R (2007) Oncology for Nurses and Healthcare Professionals: Pathology, Diagnosis and Treatment I, ( $2^{\text {nd }}$ edition). Harper and Row, London, UK, p. 37-45.

10. Creedon S, Slevin B, Quinn G, Boyle L, Doyle A, et al. (2008) Hand hygiene compliance: Exploring variating in practice between hospitals. Available at nursing times 7(2): 20-24.

11. Sessink BC, Wittenhorst RB, Anzion RP, Bos RP (1999) Exposure of Pharmacy Technicians to Antineoplastic Agents; Reevaluation after Additional Protective Measures. Archives of Environmental Health 52(3): 240-244.

12. Nygren E, Lundgren C (2006) Determination of Platinum in Workroom Air and in Blood and Urine from Nursing Staff Attending Patients Receiving Cisplatin Chemotherapy. International Archives of Occupational Environmental Health 70(3): 209-214.

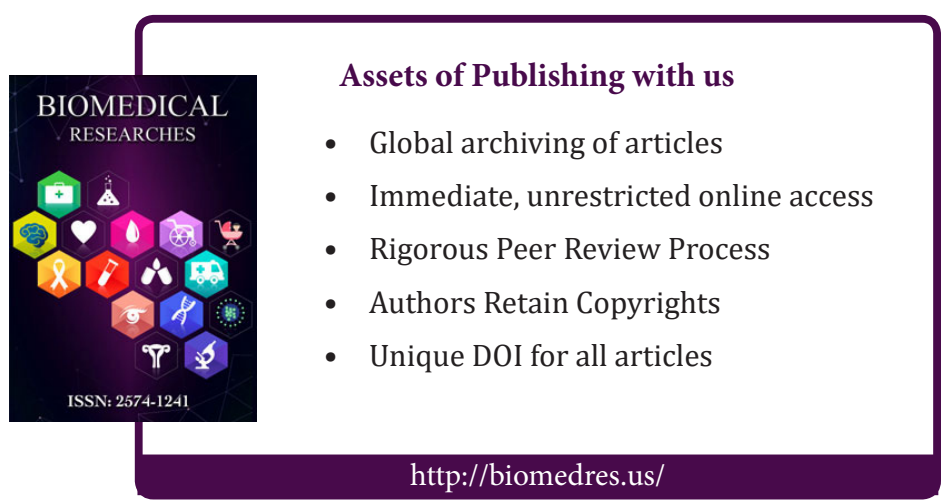

